\title{
Coronapandemie 2020
}

\section{Adelheid Schneider-Gilg}

Dr. med., Fachärztin für Allgemeine Innere Medizin, Meggen

Corona, wo kommst du her, wo willst du hin Die ganze Welt steckt mittendrin Corona, wo versteckst du dich Ein jeder dreht angstvoll nur um sich
Ende April haben wir's irgendwie geschafft Uns gegen dich, Corona, zusammengerafft Dürfen wieder fröhlich und munter sein Ist das wirklich das Ende der Pein

Oh nein, keine Illusion, wohl leider kaum Du bist ja immer noch voll im Raum Nur jetzt etwas in Schranken gehalten Weil wir pflichtbewusst Abstand halten Das Schicksal uns tief in die Seele spricht Den ganzen Körper kannst du befallen Keine Luft, kein Geruch und Schmerzensqualen Andere ziehst du nicht in deinen Bann Die glauben, dass es dich nicht geben kann

Was wollen die Welt, die Natur uns sagen Dass wir uns mit falschen Dingen plagen Mit Fortschritt, Vergnügen, Geld und Macht Anstatt des stillen Sternenhimmels Nacht

Und niemand weiss, wie es weitergeht Jeder meint, dass er es besser versteht Was heute befohlen wird und gilt morgen kaum mehr eine Rolle spielt

Bundesräte und Behörden geben sich alle Müh Reagieren aber nicht immer gerade früh Eindrücklich ist der Maskentanz schlicht Es nützt oder nicht, es hat oder nicht

Die Schweiz im Notstand - 13. März alles geschlossen Auch das Zuhause-Bleiben wird beschlossen Nur Essen und Trinken darfst noch kaufen Und drei Schritte mit Hund ums Haus rumlaufen

Österreich scheint es am besten zu machen In den USA dürfte alles zusammenkrachen Nur merkt es der dortige Chef zuletzt Da er nur auf seine nächsten Wahlen setzt
Der Engländer, der beeindruckt sehr

Zunächst hält er es für gar nicht schwer Dann erwischt es ihn, er hat aber Glück Schliesslich blickt er als Vater zurück
In Indien und Südamerika viele Tote weiterhin Neue Ausbrüche, oh Graus, in Iran und Peking Anders gelagert sind derzeit unsere Klagen Geld, Ferien, Event - was können wir wagen?

Der fröhliche Sommer kam und ging Langsam vergassen wir, wie es anfing Wieder tanzen, in Clubs, und Reisen Und miteinander fröhlich speisen

Und dann der Herbst mit Kälte und Regen Vermag das Rad wieder zurückzubewegen Ist das der Beginn der zweiten Welle? Die Realität holt uns ein, die grelle

Total verunsichert, wie es weitergeht ob wieder ein Lockdown uns vorbesteht Kulturell und sportlich eingebunden Müssen wir dich, Corona, umrunden

Bezüglich Zukunft unwissend, hilf- und ratlos Angst, Depression und Aggression werden gross Ist die Schweiz ausser Kontrolle, besonders betroffen Waren wir zu lange naiv und zu offen

Die ganze Welt steht mit dir im Krieg Nur? wer trägt schliesslich davon den Sieg So macht das Leben keinen Spass mehr Physisch-psychisch rennen wir nur hinterher

Wir müssen da durch und tapfer bleiben Uns nicht gegenseitig zusätzlich aufreiben Der einzige Hoffnungsschimmer, aber wann scheint in der Impfung zu liegen - dann. 